University of Wollongong

Research Online

Faculty of Engineering and Information

Faculty of Engineering and Information

Sciences - Papers: Part A

Sciences

2017

\title{
Vibration-induced aerodynamic loads on large horizontal axis wind turbine blades
}

Xiong Liu

University of Wollongong, xiong@uow.edu.au

Cheng Lu

University of Wollongong, chenglu@uow.edu.au

Shi Liang

Shantou University

Ajit R. Godbole

University of Wollongong, agodbole@uow.edu.au

Yan Chen

Shantou University

Follow this and additional works at: https://ro.uow.edu.au/eispapers

Part of the Engineering Commons, and the Science and Technology Studies Commons

Research Online is the open access institutional repository for the University of Wollongong. For further information contact the UOW Library: research-pubs@uow.edu.au 


\title{
Vibration-induced aerodynamic loads on large horizontal axis wind turbine blades
}

\begin{abstract}
The blades of a large Horizontal Axis Wind Turbine (HAWT) are subjected to significant vibrations during operation. The vibrations affect the dynamic flow field around the blade and consequently alter the aerodynamic forces on the blade. In order to better understand the influence of blade vibrations on the aerodynamic loads, the dynamic stall characteristics of an S809 airfoil undergoing translational motion as well as pitching motion were investigated using Computational Fluid Dynamics (CFD) techniques. Simulation results indicated that both the out-of-plane and in-plane translational motions of the airfoil affect the unsteady aerodynamic forces significantly. In order to investigate the effects of blade vibration on the aerodynamic load on a large-scale HAWT blade during its operating lifetime, an aerodynamic model based on the Blade Element-Momentum (BEM) theory and the Beddoes-Leishman (B-L) dynamic stall model was proposed. The BEM model was revised to account for the vibration-induced velocity components in the calculation of the effective angle of attack. Aerodynamic load analysis of a $5 \mathrm{MW}$ wind turbine was then performed and the impact of blade vibration on the lifetime aerodynamic fatigue loads was analysed.
\end{abstract}

\section{Keywords}

large, horizontal, axis, wind, turbine, blades, vibration, aerodynamic, induced, loads

Disciplines

Engineering | Science and Technology Studies

\section{Publication Details}

Liu, X., Lu, C., Liang, S., Godbole, A. \& Chen, Y. (2017). Vibration-induced aerodynamic loads on large horizontal axis wind turbine blades. Applied Energy, 185 (2), 1109-1119. 


\title{
Vibration-induced aerodynamic loads on large horizontal axis wind
} turbine blades ${ }^{1}$

\author{
Xiong Liu ${ }^{\mathrm{a}, \mathrm{b}}$, Cheng Lu, ${ }^{\mathrm{a},{ }^{*}}$, Shi Liang ${ }^{\mathrm{b}, \mathrm{c}}$, Ajit Godbole ${ }^{\mathrm{a}}$, Yan Chen ${ }^{\mathrm{b}}$ \\ ${ }^{a}$ School of Mechanical, Materials and Mechatronic Engineering, University of Wollongong, NSW 2522, \\ Australia \\ ${ }^{\mathrm{b}}$ School of Engineering, Shantou University, Shantou 515063, China \\ ${ }^{\mathrm{c}}$ Sinomatech Wind Power Blade Co. Ltd., Beijing 100092, China
}

\begin{abstract}
The blades of a large Horizontal Axis Wind Turbine (HAWT) are subjected to significant vibrations during operation. The vibrations affect the dynamic flow field around the blade and consequently alter the aerodynamic forces on the blade. In order to better understand the influence of blade vibrations on the aerodynamic loads, the dynamic stall characteristics of an S809 airfoil undergoing translational motion as well as pitching motion were investigated using Computational Fluid Dynamics (CFD) techniques. Simulation results indicated that both the out-of-plane and in-plane translational motions of the airfoil affect the unsteady aerodynamic forces significantly. In order to investigate the effects of blade vibration on the aerodynamic load on a large-scale HAWT blade during its operating lifetime, an aerodynamic model based on the Blade Element-Momentum (BEM) theory and the Beddoes-Leishman (B-L) dynamic stall model was proposed. The BEM model was revised to account for the vibration-induced velocity components in the calculation of the effective angle of attack. Aerodynamic load analysis of a $5 \mathrm{MW}$ wind turbine was then performed and the impact of blade vibration on the lifetime aerodynamic fatigue loads was analysed.
\end{abstract}

Keywords: Wind turbine; Unsteady aerodynamics; Dynamic stall; CFD modelling

* Corresponding author: Cheng Lu; Tel.: +61-2-4221-4639; Fax: +61-2-4221-5474.

E-mail address: chenglu@uow.edu.au

\footnotetext{
${ }^{1}$ This paper was presented at the 7th International Conference on Applied Energy (ICAE2015), March 28-31, 2015, Abu Dhabi, UAE (Paper No. 137, Original paper title: "Influence of the vibration of large-scale wind turbine blade on the aerodynamic load").
} 


\begin{tabular}{|llll|}
\hline Nomenclature & & \\
$a$ & axial flow induction factor, dimensionless & $t$ & time (s) \\
$a^{\prime}$ & tangential flow induction factor, dimensionless & $T$ & axial force $(\mathrm{N})$ \\
$c$ & chord length (m) & $U$ & wind velocity $\left(\mathrm{m} \mathrm{s}^{-1}\right)$ \\
$C_{D}$ & drag coefficient, dimensionless & $W$ & relative airflow velocity $\left(\mathrm{m} \mathrm{s}^{-1}\right)$ \\
$C_{L}$ & lift coefficient, dimensionless & & \\
$f$ & oscillation frequency (Hz) & Greek letters \\
$F$ & force (N) & $\alpha$ & angle of attack (rad) \\
$k$ & reduced frequency, dimensionless & $\beta$ & inclination angle (rad) \\
$M$ & moment (N m) & $\rho$ & air density $\left(\mathrm{kg} \mathrm{m} \mathrm{m}^{-3}\right)$ \\
$Q$ & torque (N m) & $\Omega$ & rotor angular velocity $\left(\mathrm{rad} \mathrm{s}^{-1}\right)$ \\
$r$ & radius of blade section on blade (m) & $\phi$ & inflow angle (rad) \\
$R$ & rotor radius (m) & & \\
\hline
\end{tabular}

\section{Introduction}

In the last decade, the development of renewable energy sources has attracted increasing interest due to the depletion of fossil-fuel reserves, the world's ever-growing energy consumption, and the threat of global warming [1-4]. Among the various renewable energy alternatives, wind energy is considered to be the most cost-effective of all the currently exploited renewable energy sources and has shown the fastest growth [5-8]. At the end of 2014, the global cumulative installed wind power capacity reached $369 \mathrm{GW}$, an increased of $132 \%$ compared to $159 \mathrm{GW}$ in 2009 [9].

Along with the rapid growth of the application of wind energy, increasingly large Horizontal Axis Wind Turbines (HAWTs) have been developed. This is intended to make wind turbines competitive over other energy generation systems, as the power captured by a HAWT is proportional to the swept area of the rotor [10]. The world's largest HAWT has already reached a rotor diameter of $164 \mathrm{~m}$, with a rated power of 8 MW. A 20 MW HAWT design was demonstrated to be feasible by the European project 'UpWind' and it may be implemented by 2020 [11]. The increase in power capacity of the wind turbine leads to the upscaling of the turbine structure. At the same time, the components need to be optimised to have less weight to ensure cost-effective and efficient energy conversion. This consideration results in more slender, lighter, and therefore more flexible blades for large-scale HAWTs [10]. Inevitably, the blade of a large-scale HAWT will 
experience more severe vibrations during operation. Fig. 1 shows the simulation results of the deflection and vibration-induced velocity at the blade tip of the NREL 5 MW reference wind turbine [12] operating in turbulent wind with an average wind speed of $12 \mathrm{~m} \mathrm{~s}^{-1}$. It shows that the turbine blades undergo significant deflection and vibration in both the out-of-plane and in-plane directions (Fig. 1a). The maximum vibrationinduced velocity at the blade tip can reach $9 \mathrm{~m} \mathrm{~s}^{-1}$ and $2.7 \mathrm{~m} \mathrm{~s}^{-1}$ in the out-of-plane and in-plane directions respectively (Fig. 1b), which are already non-negligible compared to the sectional linear velocity due to rotation and the inflow wind velocity.

In the design stage of wind turbines, a critical task is to accurately predict the unsteady aerodynamic loads generated due to the unsteady nature of the environment in which they typically operate [13]. This is essential for a correct estimation of blade fatigue life [14]. For modern HAWTs, the design of many wind turbine components is governed by fatigue rather than ultimate load because of the highly unstable operating conditions $[14,15]$. Wind turbulence, yaw, pitch and rotational speed regulations can all lead to dynamic variations in the Angle Of Attack (AOA) of the airfoil, resulting in dynamic stall phenomena $[13,16,17]$. The associated unsteady aerodynamic loads are usually calculated using a dynamic stall model. The vibrations of the blade can also affect the dynamic change of the AOA of the blade sections and consequently alter the unsteady aerodynamic forces, especially for large-scale wind turbines with more flexible blades. Therefore, in order to ensure safe design of the wind turbine components, a better understanding of the influence of blade vibration on the unsteady aerodynamic loads and their effects on the blade fatigue life is necessary.

\section{Literature review}

\subsection{Dynamic stall}

Dynamic stall phenomena of pitching airfoils have been studied for many years and a number of analytical models have been developed. They are used to evaluate the effects of unsteady loads arising due to the rapid variations of the AOA of an airfoil. In the current wind turbine industry, dynamic stall models are widely used for load analysis in the design stage, as dynamic stall significantly affects the fatigue loads as well as 
the ultimate loads. The first analytical dynamic stall model was the Boeing-Vertol model [18], based on a relationship between the dynamic stall angle and static stall angle. From this relationship a dynamic AOA is determined and the load coefficients are interpolated from the static data. Tran and Petot [19] developed the ONERA model, in which the load coefficients are described by a differential equation. The equation is split into a 'linear' domain determined by a first-order differential equation for low AOA, and a 'stall' domain determined by a second-order differential equation for high AOA regions. Øye [20] proposed a model which omits the transient effects of the attached flow, and represents the dynamic stall by introducing a first-order filter on an equivalent static degree of attachment, obtained by a simple interpolation relation. Beddoes and Leishman [21] proposed a dynamic stall model combining the flow delay effects of the attached flow with an approximate representation of the development and the effect of separation. This model was originally developed for an analysis of helicopter rotor dynamics. It therefore includes a representation of the unsteady attached flow depending on the Mach number and a rather complex structure of the equations representing the time delays. Larsen et al. [22] presented a model for the aerodynamic lift of wind turbine airfoils under dynamic stall, based on the effects of various flow conditions with three basic features considered: the time delay under fully attached flow situations, the time delay in the motion of the separation point, and a contribution from leading edge separation vortex and pressure peak. Of the above models, the BeddoesLeishman (B-L) model is the most popular and has been widely used in helicopter and wind turbine analyses. With the increasing application of wind turbines in recent years, efforts have been made to improve the B-L model for the prediction of unsteady aerodynamic loads on wind turbine airfoils. Hansen et al. [23] presented a state-space formulated version of the B-L dynamic stall model considering the operating condition of wind turbine airfoils, which neglects the compressibility effects and flow separation initiated from the leading edge. Gupta and Leishman [24] proposed modifications to the B-L model in order to improve its validity over a wider range of $\mathrm{AOA}$ and operating Reynolds numbers representative of wind turbines. Prediction results of an oscillating S809 airfoil by the modified model showed good agreement with measurements. Sheng et al. [25] also proposed modifications to the B-L model for low Mach numbers, including a new stallonset criterion, a new modelling of the return from the stall state, a new version of the formula for chordwise force, and a revision of the dynamic vortex formation. In the prediction of ramp-up and oscillatory tests of both NACA 0012 and S809 airfoils, the modified model showed much better performance than the original 
model.

Due to the availability of enhanced computing resources, Computational Fluid Dynamics (CFD) techniques have also been used to study the unsteady aerodynamics of airfoils. Akbari and Price [26] studied the unsteady flow over an oscillating airfoil. The effects of several parameters are investigated, including the reduced frequency, average AOA, location of the pitch axis and Reynolds number. They found that the reduced frequency has the most influence on the flow field. Martinat et al. [27] investigated the dynamic stall of a NACA 0012 airfoil using three turbulence models. The motion of pitching as well as the simultaneous motion of pitching and horizontally oscillating were studied. It was found that the longitudinal oscillation causes the dynamic stall to occur earlier. This leads to a larger area of the hysteresis cycle, due to a rise in speed during the upstroke part of the motion and a reduction in speed during the downstroke part. Sarkar and Venkatraman [28] studied the influence of the pitch angle on the dynamic stall behaviour of a symmetric airfoil. In contrast to other studies, they considered much higher AOA in the post-stall regime and found that when varying the pitching angle in this regime, the dynamic stall behaviour would be significantly impacted. Wang et al. [29] used two turbulence models, the $k$ - $\omega$ model and the SST $k$ - $\omega$ model, to study the dynamic stall of an oscillating NACA 0012 airfoil at low Reynolds number. They found that the SST $k$ - $\omega$ model was superior. Gharali and Johnson [30] simulated the dynamic stall of an S809 airfoil for several Reynolds numbers and a wide range of reduced frequency values. It was found that the behaviour of aerodynamic coefficients, vorticity fields and velocity fields are very sensitive to the reduced frequency. Also, dynamic stall simulation of eroded airfoils showed that erosion of the airfoil could greatly affect the wind turbine performance. Karbasian et al. [31] investigated the effect of acceleration on the dynamic stall of wind turbine airfoils. As in the case of rotation of an element of the blade in HAWTs, the dynamic stall evaluation was performed with a 'heaving' motion in one direction. They found that the airfoil acceleration has a significant effect on the lift, while the effect on the drag is negligible. Although CFD simulations continue to be too expensive for use in routine engineering analyses of wind turbines, the above studies indicate that CFD methods can help us better understand the flow and pressure changes occurring during a dynamic stall cycle. Using the 'dynamic mesh' technique in CFD, unsteady aerodynamic loads associated with pitching motion 
$[26,28-30]$ as well as translational motion $[27,31]$ of the airfoil can be simulated. This suggests the feasibility of using CFD techniques to investigate the effects of the vibration-induced unsteady velocity components of the airfoil on the aerodynamic loads.

\subsection{Blade flexibility}

In recent years, the need to better understand the influence of blade flexibility on turbine performance and loads due to the development of increasingly large HAWTs has been keenly felt. Ahlström [32] investigated the impact of blade deflection on the aerodynamic performance and loads by varying the flexibility of the blade using scaled mass and stiffness. He found that the change in blade flexibility may considerably affect the power production and blade loads. However, as he focused on the effects of blade deformation, the vibration-induced velocities of the blade were not considered in the aerodynamic solution. Bazilevs et al. [33] proposed a numerical Fluid-Structure Interaction (FSI) model for wind turbine blade simulation. In the model, the blade deformation is able to be automatically considered in the aerodynamics calculation. Preliminary simulations were carried out and it was found that the aerodynamic torque for the flexible blade exhibits low-magnitude, high-frequency oscillations, whereas the rigid blade torque is free of oscillations. Yu et al. [10] presented an FSI model similar to the model proposed by Bazilevs et al. [33] but in a loosely coupled manner. As in the study of Bazilevs et al., only blade deformation was considered due to the limitation of numerical methods. Yu et al. [10] pointed out that the blade deformation has a non-negligible influence on the aerodynamic loads for large-scale wind turbines, and thus the effect should be accounted for properly. Dai et al. [34] recommended the inclusion of blade vibration velocities in the Blade ElementMomentum (BEM) theory. They carried out simulations assuming a steady free stream wind with considerations of wind shear and tower shadow effects, and found that the fluctuation amplitudes and average values of the blade loads varied considerably when taking the blade vibration into account. In their study, a hypothetical angular velocity of blade vibration is used to represent the vibration of the whole blade, which probably does not reflect the real local vibration scenario at different blade sections. Mo et al. [35] presented an coupled aeroelastic analysis of the wind turbine blade, using BEM theory for aerodynamic load calculation coupled with a structural response solution model using Multi-Body System (MBS) theory. They stated that the blade vibration and deformation may have a significant effect on the aerodynamic load, and 
thus should not be ignored. However, in their study, the main focus was an evaluation of the influence of dynamic stall on the unsteady aerodynamic loads. The coupled aeroelastic analysis was carried out only for very simple load cases without considering the dynamic stall. It is unlikely that this procedure reflects the influence of blade vibration on the unsteady aerodynamic load on the blade if turbulent wind field is considered. In the above numerical studies, influence of the structural response of the flexible blade on the aerodynamic loads was usually studied by considering the blade deformation only. This is mainly due to the limitation of the numerical methods. A numerical simulation including both a turbulent wind field and with consideration of the feedback of blade vibrations is currently not achievable. In analytical models for load analysis, the vibration-induced velocities can be introduced into the BEM theory and the dynamic stall model. But comprehensive studies on the effects of vibration-induced velocities on the dynamic stall behaviour and fatigue characteristics of an wind tubine blade are still very limited. However, such information is likely to be very helpful for the safe design of large-scale HAWTs using more flexible blades.

In this paper, CFD models designed to simulate the dynamic stall behaviour of an S809 airfoil undergoing various types of motion are presented to evaluate the impact of unsteady translational motion on the aerodynamic loads of the airfoil. Validation of the CFD models is carried out using measurements from wind tunnel tests carried out by Ramsay et al. [36]. Dynamic stall characteristics of the S809 airfoil undergoing out-of-plane motion and a combination of pitching and in-plane motion are simulated and the necessity of incorporating the vibration-induced unsteady velocity components into the calculation of AOA of a wind turbine airfoil is discussed. In order to obtain a comprehensive understanding of the influence of blade vibrations on the aerodynamic loads, an aerodynamic load analysis of a $5 \mathrm{MW}$ wind turbine is carried out using the BEM theory $[14,37]$ and the B-L dynamic stall model $[21,24]$. The effect of blade vibration on the lifetime aerodynamic fatigue loads on the blade is then investigated.

\section{Numerical method}

The dynamic stall behaviour of three types of airfoil motion was investigated: pitching motion, out-of-plane motion, and a combination of pitching and in-plane motion (Fig. 2). The pitching motion was specified as in the experiments carried out by Ramsay et al. [36], intended to validate the performance of CFD models. The 
pitch oscillation about the $1 / 4$ chord is described by:

$$
\alpha=\alpha_{0}+\alpha_{m} \sin (2 \pi f t)
$$

where $\alpha_{0}, \alpha_{\mathrm{m}}$ and $f$ denote mean AOA, pitch oscillation amplitude and oscillation frequency respectively. The 'reduced' frequency often used in the study of an oscillating airfoil is defined by:

$$
k=(\pi f c) / U_{\infty}
$$

where $c$ is the chord length and $U_{\infty}$ the free stream wind velocity.

The out-of-plane motion case is set up to investigate the dynamic stall caused by translational out-of-plane motion, because in this case the blade experiences the strongest vibrations. Assuming that the out-of-plane motion is governed by:

$$
x=x_{m} \sin (2 \pi f t+\varphi)
$$

where $x_{m}$ is the amplitude of the out-of-plane motion, the resulting effective AOA (Fig. 2) is

$$
\alpha_{e}=\arctan \left(\dot{x} / U_{\infty}\right) \approx \dot{x} / U_{\infty}
$$

for small $\dot{x} / U_{\infty}$. If the initial AOA is $\alpha_{0}$, the overall AOA is obtained as:

$$
\alpha=\alpha_{0}+\alpha_{m} \sin (2 \pi f t+\varphi-\pi / 2)
$$

Here

$$
\alpha_{m}=-2 \pi f x_{m} / U_{\infty}
$$

In the combined pitching and in-plane motion case, the pitching motion is described by Eq. (1) and the inplane motion is defined as

$$
y=y_{m} \sin (2 \pi f t)
$$

where $y_{m}$ is the amplitude of the in-plane motion. This case is intended to investigate the influence of vibrations in the in-plane direction on the dynamic characteristics of an airfoil in pitching mode.

\subsection{Computational domain}

Fig. 3a shows the two-dimensional computational domain used in the CFD simulation for the S809 airfoil, 
with the $1 / 4$ chord location of the airfoil placed at the origin. The boundaries are sufficiently far (20 times chord length) from the airfoil to simulate an effectively unbounded flow field. The computational domain was discretised in the form of triangular cells, with mesh refinement in the vicinity of the airfoil (Fig. 3b). About 480 nodes were placed around the airfoil boundary. To ensure accurate simulation of the boundary layer flows $[29,38]$, the height of the node adjacent to the airfoil surface was chosen to ensure that $y^{+} \leq 1 . y^{+}$ is the non-dimensional distance from the wall for a turbulent boundary layer defined as $y^{+}=\left(\rho u_{\tau} y_{P}\right) / \mu$, where $u_{\tau}$ is the friction velocity, $y_{P}$ the distance from the centre point $P$ of wall adjacent cell to the wall, and $\mu$ the dynamic viscosity of the fluid. Grid independence of the results was examined with different grid sizes and the final optimum grid contains $2 \times 10^{5}$ cells.

\subsection{Solver set-up}

The CFD software ANSYS Fluent v14 was used to solve the Unsteady Reynolds-Averaged Navier-Stokes (URANS) equations based on the Finite Volume Method (FVM). The SST $k$ - $\omega$ model was chosen for turbulence closure, as it has been successfully applied by other researchers for dynamic stall simulation [2931, 38]. The airfoil surface was defined as a 'no-slip' wall. Velocity components were specified at the inlet boundary. The two straight horizontal upper and lower segments of the domain boundary were defined as 'symmetry' boundaries. At the outlet boundary, free stream static pressure was specified. During the unsteady simulations, the ‘dynamic mesh' feature was enabled. The rigid body oscillations of the airfoil about the origin were defined by User-Defined Functions (UDFs) describing Eqs. (1), (3) and (7).

As the fluid velocity investigated in this study is low, the flow was considered incompressible and the pressure-based solver was selected. For pressure-velocity coupling, the SIMPLE algorithm was chosen. A second order upwind method for spatial discretisation was specified. The time-step was set as $0.001 \mathrm{~s}$ and the convergence criterion was defined as the residuals becoming equal to or less than $10^{-6}$.

\section{CFD simulation results}

\subsection{Pitching motion}

Two cases were simulated for the S809 airfoil undergoing pitching motion, with the conditions as specified 
in [36]. In the first case, the AOA of the airfoil was set to vary in the stall development regime, with $\alpha_{0}=8^{\circ}$, $\alpha_{m}=10^{\circ}, k=0.033$ and $U_{\infty}=25.91 \mathrm{~m} \mathrm{~s}^{-1}$. In the second case, dynamic stall in the deep stall regime was investigated, with $\alpha_{0}=14^{\circ}, \alpha_{m}=10^{\circ}, k=0.08$ and $U_{\infty}=32.98 \mathrm{~m} \mathrm{~s}^{-1}$.

Fig. 4 presents the predicted aerodynamic coefficient hysteresis loops $\left(C_{L}\right.$ : lift coefficient, $C_{D}$ : drag coefficient) in the stall development regime. The minimum lift coefficient was slightly over-predicted, while the intersection in the lift coefficient loop and the maximum $C_{L}$ value were successfully estimated. During the upstroke, the lift was mostly under-predicted. Both the measured and simulated lift curves are linear up to about $13^{\circ}$, but the slope of the simulated curve is slightly lower than that of the measured one. During the downstroke, the lift coefficient was slightly under-predicted at high AOA. At low AOA, it was slightly overpredicted. The measurements of the drag coefficient were consistently well predicted at low AOA. But for $\mathrm{AOA}>13^{\circ}$ during the upstroke, it was considerably over-predicted. This may be due to the fact that in the experiment, only the pressure drag was measured, whereas the simulation produces the total drag and at high AOA, the induced drag becomes significant.

The simulation results for the airfoil pitch oscillating in the deep stall regime are shown in Fig. 5. The lift coefficient was predicted well, especially during the upstroke. When the AOA far exceeds the static stall point, the flow around the airfoil becomes very unsteady and violent, resulting in larger discrepancies. This is mainly due to over-estimation of the suction contribution of Leading Edge Vortex (LEV) growing and spanning the upper surface (see Fig. 6). From about $18.8^{\circ}$ to $21^{\circ}$, the $S S T k$ - $\omega$ model predicted a sudden increase in the slope of the $C_{L}$ curve. This is similar to the simulation results by other researchers [29, 38, 39]; however this does not take place in reality for the S809 airfoil as the measurements indicate. The second rise in the lift coefficient after stall is due to the high-vorticity secondary LEV, which grows rapidly and creates a second peak in the lift curve [38]. The appearance of the second lift peak was successfully predicted but with a much lower magnitude than the measurements. During the downstroke, the proposed CFD model still fared quite well, although for dynamic stall occurring in deep stall regime, an accurate prediction of the downstroke flow usually cannot be warranted [39]. As in the case of the CFD simulation for the stall 
development regime, the drag coefficient was successfully predicted at low AOA, but at high AOA during the upstroke, it was over-predicted.

Overall, the CFD models showed a satisfactory performance not only in the stall development regime but also in the deep stall regime. The predicted trends of the force coefficients within a dynamic stall cycle are consistent with the measured trends. The range of variation of the aerodynamic coefficients was successfully estimated and there was mostly good agreement between the predicted and measured hysteresis loops. This shows that the CFD model adopted here can be used to predict the unsteady aerodynamics of an oscillating airfoil.

\subsection{Out-of-plane motion}

The out-of-plane motion of the airfoil was intentionally defined to be equivalent to the cases studied above and here the deep stall regime case was selected. In Eqs. (5) and (6), the values of $x_{m}$ and $\varphi$ were obtained as -0.5 and $\pi / 2$ respectively. Thus the motion of the airfoil was governed by $x=-0.5 \sin (2 \pi f t+\pi / 2)$, where $k=$

0.08 , giving a maximum velocity of $5.8 \mathrm{~m} \mathrm{~s}^{-1}$, which is comparable to the maximum vibration-induced velocity in the out-of-plane direction shown in Fig. $1 b$.

Fig. 7 compares the predicted lift and drag coefficient loops for the airfoil undergoing out-of-plane motion with those of a pitching airfoil. The overall trends are similar. Similar to the pitch oscillation case, the phenomenon of LEV development over the upper surface of the airfoil can be seen in Fig. 8 during the upward motion (equivalent to the upstroke pitching). However, when undergoing out-of-plane motion, the vortex development over the airfoil surface is not as pronounced as when undergoing pitching motion. During the upward motion, the lift coefficient of the out-of-plane oscillating airfoil is mostly lower than when pitching, while during the downward motion the lift coefficient is mostly higher, resulting in a narrower loop. As shown in Fig. 8c, the equivalent AOA at which the LEV covers the entire upper surface occurs at a lower value compared to the pitch oscillation case (Fig. 6c). At this AOA, the lift coefficient is approaching its maximum value, suggesting an imminent stall. This is reflected in Fig. 7, where it is seen that the stall of the airfoil undergoing out-of-plane motion occurs much earlier. In contrast with the lift 
coefficient loop, the drag coefficient loop of the out-of-plane oscillating airfoil is mostly wider than that for the pitching airfoil. At low AOA, a much higher drag coefficient was predicted, while at high AOA, a lower drag coefficient and narrower loop were predicted.

The above simulation indicates that the out-of-plane oscillation of the airfoil can cause significant unsteady aerodynamic loads. The dynamic stall of the out-of-plane oscillation can be comparable to an equivalent pitching oscillation.

\subsection{Combined pitching and in-plane motion}

In this case, the in-plane translational motion was coupled with the pitching motion. For comparison, the same pitch oscillation in the deep stall regime studied above was specified. The in-plane motion was defined by $y=0.227 \sin (2 \pi f t)$, where $k=0.08$, giving a maximum velocity of $2.64 \mathrm{~m} \mathrm{~s}^{-1}$, which is close to the maximum vibration-induced velocity in the in-plane direction shown in Fig. 1 b.

As shown in Fig. 9, the combined motion case shows wider aerodynamic coefficient hysteresis loops than the 'pitching only' case. This result is similar to the simulation results for a NACA 0012 airfoil carried out by Martinat et al. [27]. In addition, the stall of the combined motion occurs at a smaller AOA by nearly $2.5^{\circ}$. This is because during the upstroke, the AOA is increased due to the in-plane motion, resulting in higher aerodynamic coefficients and advanced stall point; while during downstroke, the AOA is reduced due to the in-plane motion, leading to lower aerodynamic coefficients. The results indicate that the in-plane vibration can also affect the aerodynamic forces significantly.

Overall, the above simulation results suggest that the translational motion superimposed on a pitching airfoil greatly affect its unsteady aerodynamic loads, which implies that the effects of vibrations experienced by the large-scale wind turbine blade during operation are significant. This makes it necessary to account for the unsteady aerodynamic loads caused by blade vibration in the wind turbine design stage. In the analytical models for wind turbine load analysis, the vibration-induced unsteady velocity components of the blade section in the out-of-plane and in-plane directions should be considered in the calculation of the AOA for 
dynamic stall analysis. Although there exists certain discrepancy in the force coefficients produced by different types of motions, it is acceptable to account for the vibration-induced velocities using an effective AOA, as the analytical models used in wind turbine load analysis are not meant to capture all the details of the flow, but to model the overall characteristics in a fast and efficient way [22].

\section{Effects of vibration-induced velocity on aerodynamic loading}

In order to evaluate the effects of blade vibration on the aerodynamic loading, an aerodynamic load analysis of a 5 MW HAWT was carried out. Table 1 shows the wind turbine parameters. Fig. 10 presents the coordinate system for blade loads and deflection: $Z$ is along the blade axis; $X$ is perpendicular to $Z$ and pointing towards the tower for an upwind turbine; and $Y$ is perpendicular to $Z$ and $X$, to give a right-handed coordinate system.

\subsection{Aerodynamic model}

The aerodynamic loads acting on a blade section were estimated using the BEM theory [14, 37], while the unsteady aerodynamic force coefficients due to the dynamic change of AOA was evaluated using the B-L dynamic stall model $[21,24]$. The BEM theory is based on the momentum theory and blade element theory. In the momentum theory, the wind turbine rotor is considered as an energy-extracting actuator disc rotating in a stream tube. The axial force $T$ and torque $Q$ per unit length on the annulus of the actuator disc can then be obtained based on the conservation of momentum in both axial and rotational directions:

$$
\begin{gathered}
\frac{\mathrm{d} T}{\mathrm{~d} r}=4 \pi \rho U^{2} r a(1-a) \\
\frac{\mathrm{d} Q}{\mathrm{~d} r}=4 \pi \rho \Omega U r^{3} a^{\prime}(1-a)
\end{gathered}
$$

where $\rho$ is the air density, $U$ the upstream wind velocity, $r$ the radial distance of the blade section from the axis of rotation, $a$ the axial flow induction factor, $a^{\prime}$ the tangential flow induction factor, and $\Omega$ the rotor angular velocity.

The blade element theory is based on airfoil aerodynamics. Considering a blade section at radius $r$, the normal force and tangential force per unit length are given as (refer to Figs. 10 and 11): 


$$
\begin{aligned}
\frac{\mathrm{d} F_{X}}{\mathrm{~d} r} & =\frac{1}{2} \rho W^{2} c\left(C_{L} \cos \phi+C_{D} \sin \phi\right) \\
\frac{\mathrm{d} F_{Y}}{\mathrm{~d} r} & =-\frac{1}{2} \rho W^{2} c\left(C_{L} \sin \phi-C_{D} \cos \phi\right)
\end{aligned}
$$

where $W$ is the relative airflow velocity and $\phi$ the inflow angle. Eqs. (8) to (11) can be solved using NewtonRaphson iteration.

In the original BEM model, the inflow angle of the blade section is obtained by (see Fig. 11):

$$
\phi=\arctan \frac{U_{\infty}(1-a)}{\Omega r\left(1+a^{\prime}\right)}
$$

If the out-of-plane and in-plane vibration-induced velocity components are considered, the equation for calculating the inflow angle can be modified to:

$$
\phi=\arctan \frac{U_{\infty}(1-a)-\dot{x}}{\Omega r\left(1+a^{\prime}\right)-\dot{y}}
$$

As the AOA $\alpha=\phi-\beta$ ( $\beta$ is the inclination angle of blade section to the rotor plane, which is the sum of the blade section twist angle and the blade pitch angle), using Eq. (13), the AOA time series including the effect of the airfoil vibrations can then be figured out and fed into the B-L model to obtain the dynamic $C_{L}$ and $C_{D}$.

\subsection{Aerodynamic load calculation}

Load calculation of the $5 \mathrm{MW}$ wind turbine was carried out for power production assuming a turbulent wind of $12 \mathrm{~m} \mathrm{~s}^{-1}$ mean wind speed. The total simulation duration was 600 s. Fig. 12 shows the results of vibrationinduced velocities, AOA, aerodynamic force coefficients, and aerodynamic forces per unit length at $99 \%$ rotor radius. For clarity, results for only the first $50 \mathrm{~s}$ are displayed. As shown in Fig. 12a, the blade section experiences considerable vibrations in the out-of-plane and in-plane directions. After about $30 \mathrm{~s}$, the amplitude of the vibration-induced velocity in the in-plane direction becomes much larger than before. This is because of the occurrence of pitch regulation, leading to large inclination angle of the blade section and resulting in larger in-plane component of the flapwise vibration-induced velocity. Fig. 12b shows a comparison between the time series of the AOA with and without the effect of the vibration-induced velocities. Clearly, there is stronger fluctuation in the AOA when considering the vibration-induced 
velocities, leading to stronger fluctuations in the lift and drag coefficients shown in Figs. 12c and 12d. However, this effect on the drag coefficient after $30 \mathrm{~s}$ is less severe (Fig. 12d). This is also due to the pitch regulation which reduces the AOA significantly, while at low AOA, the drag coefficient of the airfoil is almost constant. Figs. 12e and 12f display the resulting aerodynamic forces per unit length. When considering the vibration-induced velocities, a consistently stronger fluctuation in the normal force can be observed. The fluctuation of tangential force considering the vibration-induced velocities, before $30 \mathrm{~s}$, is also stronger than that without consideration of the vibration-induced velocities. But after $30 \mathrm{~s}$, owing to pitch regulation, the effect of vibration-induced velocities leads to slight reduction of the magnitude of the fluctuation of the tangential force. This indicates that the larger inclination angle caused by pitch regulation may reduce the effects of the vibration on the fluctuation magnitude of the tangential force.

A spectral analysis was carried out on the simulated $600 \mathrm{~s}$ time series of the aerodynamic forces at $99 \%$ rotor radius, as it can provide a useful means of understanding the load variations. Fig. 13 shows the auto-spectra of the aerodynamic forces. Clearly, both the normal and tangential forces are dominated by peaks at the rotational frequency of $0.24 \mathrm{~Hz}(1 P)$. These are caused mainly by the rotational sampling of turbulence by the blade as it sweeps around, repeatedly passing through turbulent eddies. Seen from Fig. 13, when considering the vibration-induced velocities, the resonance peak of both normal and tangential forces at $1 P$ reduces significantly. This implies that the unsteady aerodynamic loads caused by the blade vibration may introduce more fatigue damage to the blade.

\subsection{Lifetime aerodynamic loading analysis}

In order to understand the influence of the blade vibrations on aerodynamic fatigue loading on the blade during its operating lifetime, an aerodynamic load analysis of the wind turbine was performed. The aerodynamic loads acting on the wind turbine blade were calculated assuming turbulent wind fields with 11 different mean wind speeds ranging from $4 \mathrm{~m} \mathrm{~s}^{-1}$ to $24 \mathrm{~m} \mathrm{~s}^{-1}$. Three random turbulent 'seeds' were used for each mean wind speed and each of the wind time series lasts $600 \mathrm{~s}$. In total there were 33 load cases simulated. The wind turbine class for the 5 MW machine was considered to be IEC IA [40], with a Weibull wind speed distribution [14] with an annual mean wind speed of $10 \mathrm{~m} \mathrm{~s}^{-1}$ and a shape parameter of 2. The 
total number of load cases for each mean wind speed throughout the 20 year lifetime was scaled from the corresponding Weibull hours.

To enable meaningful comparison, fatigue damage-equivalent loads were used to equate the fatigue damage represented by rainflow cycle counted data to that caused by a single load range repeating at a single frequency [14]. Based on Miner's rule [41, 42], the damage-equivalent load is given by:

$$
L_{e q}=\left[\sum_{i=1}^{N} \frac{\left(L_{a i}+m_{f} \mid L_{m i}\right)^{m}}{N}\right]^{\frac{1}{m}}
$$

where $L_{a i}$ and $L_{m i}$ are the amplitude and mean value of the load cycle respectively; $m$ is the slope of the SN curve, $N$ the number of cycle repetitions in the turbine lifetime, and $m_{f}$ the mean load sensitivity factor $\left(m_{f}=\right.$ $0.00035 \sigma_{u}-0.1$, where $\sigma_{u}$ is the ultimate stress for the material) [41].

The slope of the SN curve was chosen as $m=10$, which is typically chosen for Glass-Reinforced Plastic (GRP) [40]. The damage-equivalent loads were then estimated for each load component assuming $1.37 \times 10^{8}$ cycles in the turbine lifetime of 20 years. The obtained damage equivalent load ranges of the aerodynamic forces per unit length on the two blade sections are shown in Table 2. Section A is at $99 \%$ rotor radius and Section B is at $75 \%$ rotor radius. The chord lengths of sections A and B are $0.7 \mathrm{~m}$ and $2.1 \mathrm{~m}$ respectively.

Clearly, blade vibrations have a significant influence on the distributed aerodynamic fatigue loads on these two sections. Below the rated wind speed, when considering the vibration-induced velocities in the calculation of airfoil AOA, the aerodynamic fatigue loads per unit length mostly tend to be higher. It is found that the section closer to the blade tip has much higher change in the magnitude of the fatigue loads. This is mainly due to the blade tip experiencing the maximum deflection and vibration amplitude, which reduce quickly towards the blade root. The change in magnitude in the tangential fatigue load range $S_{Y}$ reduces much faster (from around $65 \%$ to $3 \%$ ) than that in the normal fatigue load range $S_{X}$ (from about $24 \%$ to $3 \%$ ). This is because Section B has larger inclination angle (due to larger twist angle), which may contribute to 
reducing the effects of vibration on the tangential load fluctuation as mentioned above. At high wind speeds, a consistent increase in the damage-equivalent load of the normal force is observed when considering the vibration-induced velocities. However, the fatigue load of the tangential force tends to be reduced, in particular at Section B, showing significant reduction in the tangential fatigue load. This may be due to the frequent pitch regulation at high wind speeds, making a large inclination angle for the blade sections. Combining all the wind speeds, the overall fatigue loads per unit length indicate that the consideration of the blade vibration leads to significant aerodynamic fatigue load increase at $99 \%$ rotor radius. The impact reduces towards the rotor axis. However at $75 \%$ rotor radius, there is still a $6 \%$ increase and significant reduction of the aerodynamic fatigue loads per unit length in the out-of-plane and in-plane directions respectively.

Table 3 shows the resulting lifetime aerodynamic fatigue loads on the blade in terms of damage-equivalent aerodynamic bending moments and aerodynamic forces at five blade sections from 5\% to $95 \%$ rotor radius. It is seen that the blade vibration has great influence on the out-of-plane damage equivalent bending moment $M_{Y}$, especially for the outer part of the blade, showing a significant increase. The impact decreases towards the blade root, but there is still a $4.5 \%$ increase at $5 \%$ rotor radius. From blade tip to blade root, the consideration of blade vibration leads to an increase of the in-plane damage-equivalent aerodynamic bending moment $\left(M_{X}\right)$ at first, but the impact is gradually reversed. At $5 \%$ rotor radius, we can see a significant reduction in $M_{X}$. This agrees with the above distributed loads analysis. As with the out-of-plane bending moment, a consistent increase in the out-of-plane damage equivalent thrust force $F_{X}$ is observed when considering the blade vibration. The impact also decreases towards the blade root. At $5 \%$ rotor radius, there is only a slight increase. This implies the consideration of blade vibration has limited effects on the fatigue load of tower bending moment. Overall, the blade vibration has considerable influence on the lifetime aerodynamic fatigue loading on the blade. In order to achieve an optimum design, considering the effects of the blade vibration in the aerodynamic load analysis is necessary. This analysis may also affect the structural strength requirements and control system design. 


\section{Conclusions}

In this study, in order to better understand the effects of blade vibrations on lifetime aerodynamic loading, CFD techniques were employed to investigate the influence of the translational motion of an S809 airfoil on the dynamic stall characteristics. In addition, an aerodynamic load analysis of a $5 \mathrm{MW}$ wind turbine blade was carried out based on the BEM theory and the B-L dynamic stall model. The fatigue damage-equivalent loads on the blade with and without considering the vibration-induced velocities were compared. It can be concluded that:

(1) CFD models using a dynamic mesh can predict satisfactory aerodynamic coefficient hysteresis loops for a moving airfoil. Good agreement with the measurements can be achieved in both stall development and deep stall regimes for a pitching S809 airfoil.

(2) The translational motion of the airfoil can significantly contribute to the dynamic stall. The out-ofplane motion can cause stall of magnitude comparable to its equivalent pitching motion. A relatively small perturbation in the in-plane direction can alter the aerodynamic force considerably. The results suggest that it would be beneficial to include the vibration-induced velocities in the calculation of airfoil AOA.

(3) The blade vibration has considerable influence on the aerodynamic fatigue loads on the blade of large-scale HAWTs. At the outer parts of the blade close to the blade tip, the blade vibration can introduce significantly excessive fatigue bending moments in both out-of-plane and in-plane directions. Close to the blade root, there would be considerable increase in the out-of-plane fatigue bending moment and significant reduction in the in-plane fatigue bending moment if the effect of the vibration-induced velocities is considered.

(4) For large-scale wind turbines, the effect of blade vibrations should be considered by using Eq. (13) for the calculation of AOA in the aerodynamic load analysis to achieve optimum structural strength and control system design.

\section{Acknowledgements}

This work was co-supported by the National Natural Science Foundation of China (Grant No. 51276106), the 
Specialized Research Fund for the Doctoral Program of Higher Education (Grant No. 20124402110005), and the Key Project of Chinese Ministry of Education (Grant No. 212130).

\section{Reference:}

[1] Chehouri A, Younes R, Ilinca A, Perron J. Review of performance optimization techniques applied to wind turbines. Applied Energy. 2015;142:361-88.

[2] Pagnini LC, Burlando M, Repetto MP. Experimental power curve of small-size wind turbines in turbulent urban environment. Applied Energy. 2015;154:112-21.

[3] Roy S, Saha UK. Wind tunnel experiments of a newly developed two-bladed Savonius-style wind turbine. Applied Energy. 2015;137:117-25.

[4] Saeidi D, Sedaghat A, Alamdari P, Alemrajabi AA. Aerodynamic design and economical evaluation of site specific small vertical axis wind turbines. Applied Energy. 2013;101:765-75.

[5] Danao LA, Edwards J, Eboibi O, Howell R. A numerical investigation into the influence of unsteady wind on the performance and aerodynamics of a vertical axis wind turbine. Applied Energy. 2014;116:11124.

[6] Melício R, Mendes VMF, Catalão JPS. Transient analysis of variable-speed wind turbines at wind speed disturbances and a pitch control malfunction. Applied Energy. 2011;88:1322-30.

[7] Rolland S, Newton W, Williams AJ, Croft TN, Gethin DT, Cross M. Simulations technique for the design of a vertical axis wind turbine device with experimental validation. Applied Energy. 2013;111:1195203.

[8] Sun H, Luo X, Wang J. Feasibility study of a hybrid wind turbine system - Integration with compressed air energy storage. Applied Energy. 2015;137:617-28.

[9] Global Wind Energy Council (GWEC). Global wind report: annual market update 2014. Brussels, Belgium: Global Wind Energy Council; 2015. 
[10] Yu DO, Kwon OJ. Predicting wind turbine blade loads and aeroelastic response using a coupled CFDCSD method. Renewable Energy. 2014;70:184-96.

[11] UpWind. Design limits and solutions for very large wind turbines. Brussels, Belgium: European Wind Energy Association; 2011.

[12] Jonkman J, Butterfield S, Musial W, Scott G. Definition of a 5-MW Reference Wind Turbine for Offshore System Development. Colorado: National Renewable Energy Laboratory (NREL); 2009.

[13] Holierhoek JG, de Vaal JB, van Zuijlen AH, Bijl H. Comparing different dynamic stall models. Wind Energy. 2013;16:139-58.

[14] Burton T, Sharpe D, Jenkins N, Bossanyi E. Wind energy handbook. New York: Wiley; 2001.

[15] Schubel PJ, Crossley RJ. Wind turbine blade design review. Wind Engineering. 2012;36:365-88.

[16] Choudhry A, Leknys R, Arjomandi M, Kelso R. An insight into the dynamic stall lift characteristics. Experimental Thermal and Fluid Science. 2014;58:188-208.

[17] Liu X, Zhang X, Li G, Chen Y, Ye Z. Dynamic response analysis of the rotating blade of horizontal axis wind turbine. Wind Engineering. 2010;34:543-60.

[18] Tarzanin FJ. Prediction of control loads due to blade stall. Journal of American Helicopter Society. $1972 ; 17: 33-46$.

[19] Tran CT, Petot D. Semi-empirical model for the dynamic stall of airfoils in view of the application to the calculation of response of a helicopter blade in forward flight. Vertica. 1981;5:35-53.

[20] Øye S. Dynamic stall simulated as time lag of separation. Denmark: Technical University of Denmark; 1991.

[21] Leishman JG, Beddoes TS. A semi-empirical model for dynamic stall. Journal of American Helicopter Society. 1989;34:3-17. 
[22] Larsen JW, Nielsen SRK, Krenk S. Dynamic stall model for wind turbine airfoils. J Fluids Struct. 2007;23:959-82.

[23] Hansen MH, Gaunaa M, Madsen HA. A Beddoes-Leishman type dynamic stall model in state-space and indicial formulations. Denmark: Risø National Laboratory; 2004.

[24] Gupta S, Leishman JG. Dynamic stall modelling of the S809 aerofoil and comparison with experiments. Wind Energy. 2006;9:521-47.

[25] Sheng W, Galbraith RAM, Coton FN. A modified dynamic stall model for low Mach numbers. Journal of Solar Energy Engineering. 2008;130:031013.

[26] Akbari MH, Price SJ. Simulation of dynamic stall for a NACA 0012 airfoil using a vortex method. J Fluids Struct. 2003;17:855-74.

[27] Martinat G, Braza M, Harran G, Sevrain A, Tzabiras G, Hoarau Y, et al. Dynamic stall of a pitching and horizontally oscillating airfoil. IUTAM Symposium on Unsteady Separated Flows and their Control. Corfu, Greece: Springer; 2007.

[28] Sarkar S, Venkatraman K. Influence of pitching angle of incidence on the dynamic stall behavior of a symmetric airfoil. European Journal of Mechanics - B/Fluids. 2008;27:219-38.

[29] Wang S, Ingham DB, Ma L, Pourkashanian M, Tao Z. Numerical investigations on dynamic stall of low Reynolds number flow around oscillating airfoils. Computers \& Fluids. 2010;39:1529-41.

[30] Gharali K, Johnson DA. Numerical modeling of an S809 airfoil under dynamic stall, erosion and high reduced frequencies. Applied Energy. 2012;93:45-52.

[31] Karbasian HR, Esfahani JA, Barati E. Effect of acceleration on dynamic stall of airfoil in unsteady operating conditions. Wind Energy. 2014:n/a-n/a.

[32] Ahlström A. Influence of wind turbine flexibility on loads and power production. Wind Energy. 2006;9:237-49. 
[33] Bazilevs Y, Hsu MC, Kiendl J, Wüchner R, Bletzinger KU. 3D simulation of wind turbine rotors at full scale. Part II: Fluid-structure interaction modeling with composite blades. International Journal for Numerical Methods in Fluids. 2011;65:International Journal for Numerical Methods in Fluids.

[34] Dai JC, Hu YP, Liu DS, Long X. Aerodynamic loads calculation and analysis for large scale wind turbine based on combining BEM modified theory with dynamic stall model. Renewable Energy. 2011;36:1095-104.

[35] Mo W, Li D, Wang X, Zhong C. Aeroelastic coupling analysis of the flexible blade of a wind turbine. Energy. 2015;89:1001-9.

[36] Ramsay R, Homan M, Gregorek G. Effects of grit roughness and pitch oscillation on the S809 airfoil. Columbus: The Ohio State University; 1995.

[37] Spera DA. Wind turbine technology: Fundamental concepts of wind turbine engineering. 2nd edition ed. New York: ASME Press; 2009.

[38] Gharali K, Johnson DA. Dynamic stall simulation of a pitching airfoil under unsteady freestream velocity. J Fluids Struct. 2013;42:228-44.

[39] Wang S, Ingham DB, Ma L, Pourkashanian M, Tao Z. Turbulence modeling of deep dynamic stall at relatively low Reynolds number. J Fluids Struct. 2012;33:191-209.

[40] Germanischer Lloyd (GL). Guideline for the certification of offshore wind turbines. Hamburg: Germanischer Lloyd WindEnergie GmbH; 2005.

[41] Lee YL, Pan J, Hathaway R, Barkley M. Fatigue testing and analysis - theory and practice. Burlington, MA: Elsevier; 2005.

[42] Miner MA. Cumulative damage in fatigue. Journal of Applied Mechanics. 1945;67:A159-A64. 


\section{Figure Captions:}

Fig. 1. Deflection and vibration-induced velocity at the blade tip of the 5 MW NREL reference wind turbine in $12 \mathrm{~m} \mathrm{~s}^{-1}$ turbulent wind

Fig. 2. Schematic of airfoil motion types

Fig. 3. Computational domain and mesh for the airfoil

Fig. 4. Lift and drag coefficients for pitch oscillation with $\alpha_{0}=8^{\circ}, \alpha_{\mathrm{m}}=10^{\circ}$ and $k=0.033$

Fig. 5. Lift and drag coefficients for pitch oscillation with $\alpha_{0}=14^{\circ}, \alpha_{\mathrm{m}}=10^{\circ}$ and $k=0.08$

Fig. 6. Streamlines over the airfoil for pitch oscillation with $\alpha_{0}=14^{\circ}, \alpha_{\mathrm{m}}=10^{\circ}$ and $k=0.08$

Fig. 7. Lift and drag coefficients for out-of-plane motion as $x=-0.5 \sin (2 \pi f t+\pi / 2)$, compared with those under pitching motion

Fig. 8. Streamlines over the airfoil for out-of-plane motion as $x=-0.5 \sin (2 \pi f t+\pi / 2), \alpha$ is the effective AOA

Fig. 9. Lift and drag coefficients for combined pitching and in-plane motion, compared with those under pitching motion

Fig. 10. Blade coordinate system for loads and deflection [40]

Fig. 11. Velocity diagram for a vibrating blade section

Fig. 12. Time series of vibration-induced velocity, AOA, force coefficient, and aerodynamic force per unit length at $99 \%$ rotor radius of the blade in $12 \mathrm{~m} \mathrm{~s}^{-1}$ turbulent wind

Fig. 13. Spectra of aerodynamic force per unit length at $99 \%$ rotor radius of the blade in $12 \mathrm{~m} \mathrm{~s}^{-1}$ turbulent wind

\section{Table Captions:}

Table 1 Parameters of the studied wind turbine

Table 2 Damage-equivalent load ranges of aerodynamic forces per unit length on two blade sections $\left(S_{X}\right.$ and $S_{Y}$ are the damage equivalent load ranges of $\mathrm{d} F_{X} / \mathrm{d} r$ and $\mathrm{d} F_{Y} / \mathrm{d} r$ respectively without consideration of the blade vibration; $S_{X}{ }^{\prime}$ and $S_{Y}{ }^{\prime}$ are the damage equivalent load ranges of $\mathrm{d} F_{X} / \mathrm{d} r$ and $\mathrm{d} F_{Y} / \mathrm{d} r$ respectively with consideration of the blade vibration. $\delta$ represents relative \% deviation, $\delta=\left(S^{\prime}-S\right) /$ $S)$

Table 3 Damage-equivalent aerodynamic bending moments and aerodynamic forces on the blade $(M$ and $F$ are the damage equivalent bending moment and force respectively without consideration of the blade vibration; $M^{\prime}$ and $F^{\prime}$ are the damage equivalent bend moment and force respectively with consideration of the blade vibration. $\delta$ represents relative \% deviation, $\delta=\left(X^{\prime}-X\right) / X$.) 

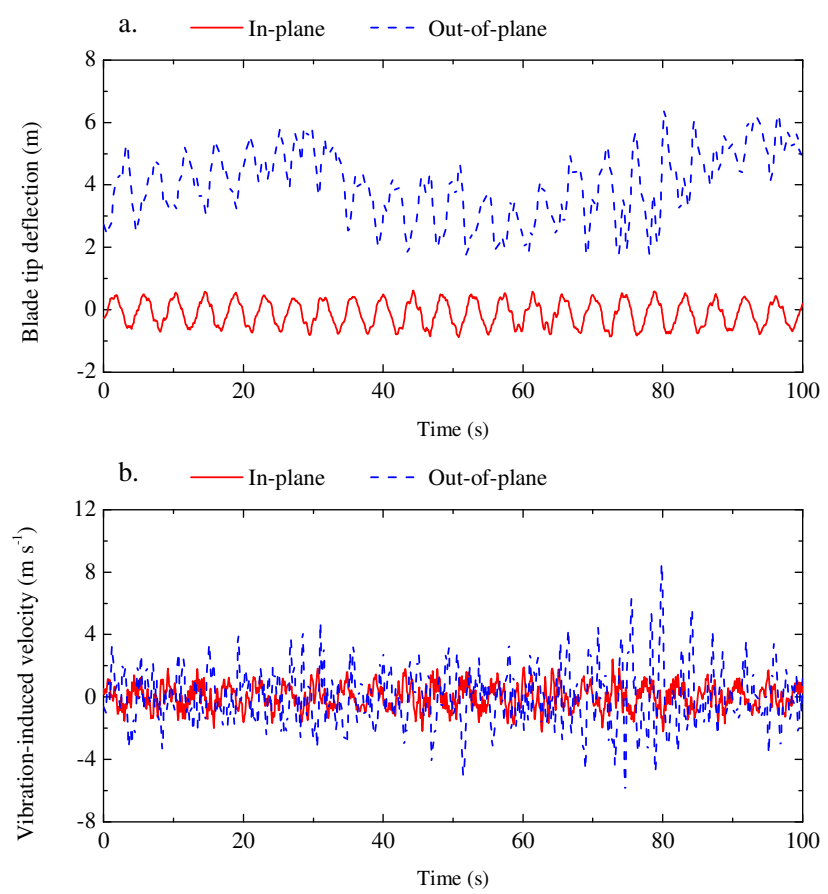

Fig. 1. Deflection and vibration-induced velocity at the blade tip of the $5 \mathrm{MW}$ NREL reference wind turbine in $12 \mathrm{~m} \mathrm{~s}^{-1}$ turbulent wind

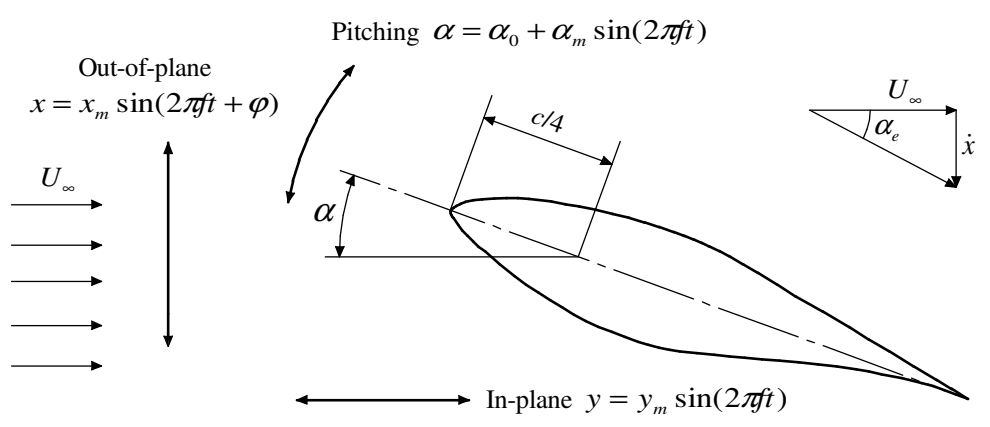

Fig. 2. Schematic of airfoil motion types

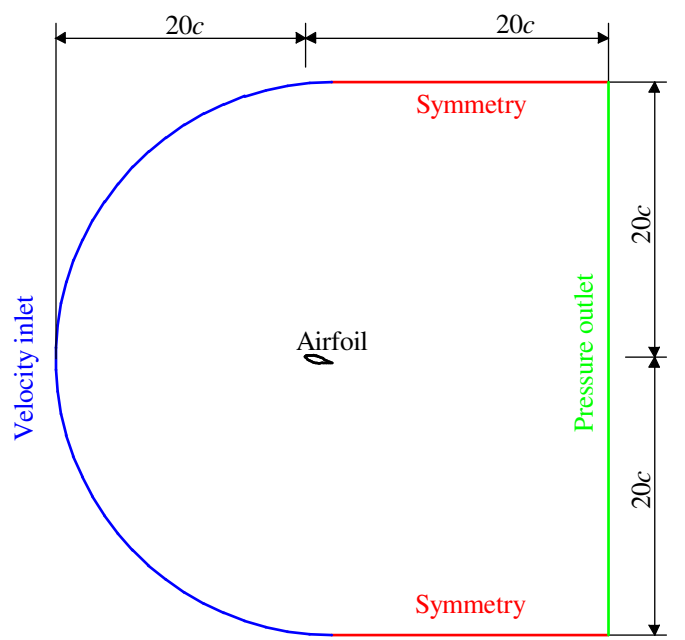

a. Computational domain

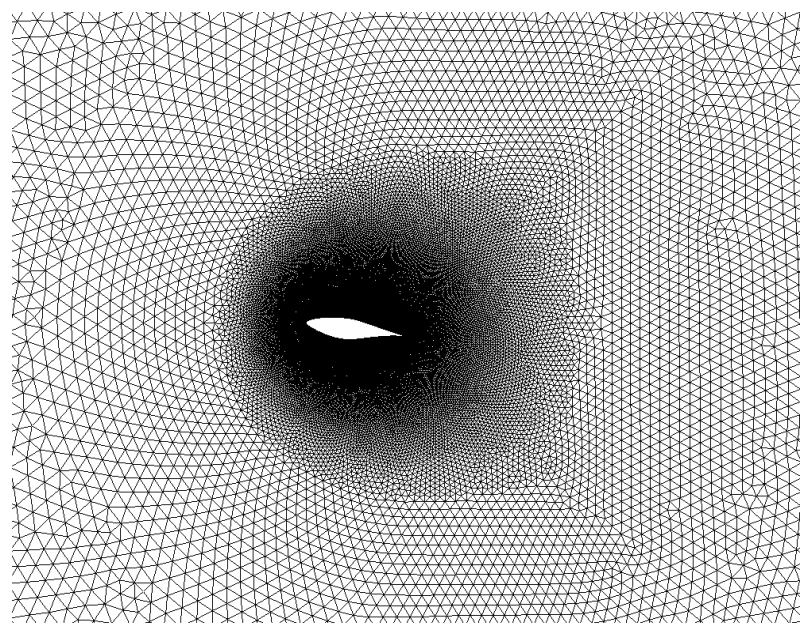

b. Mesh around the airfoil

Fig. 3. Computational domain and mesh for the airfoil 

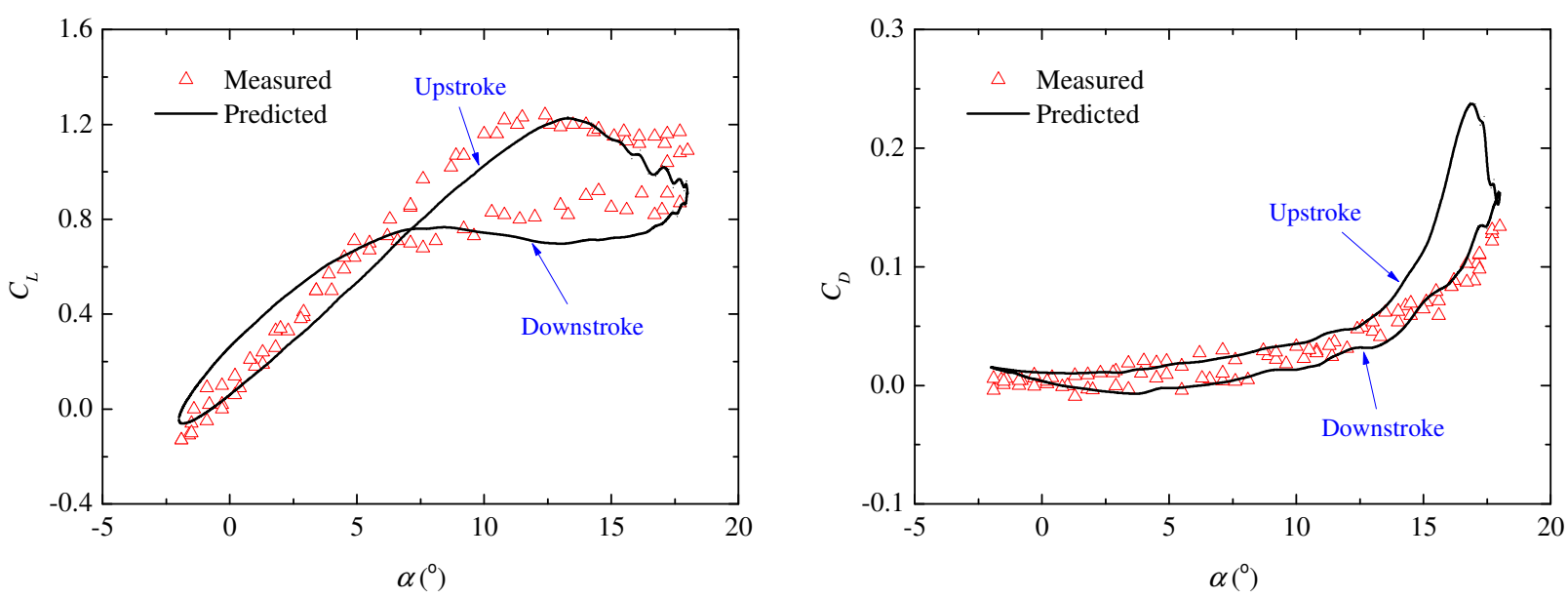

Fig. 4. Lift and drag coefficients for pitch oscillation with $\alpha_{0}=8^{\circ}, \alpha_{\mathrm{m}}=10^{\circ}$ and $k=0.033$
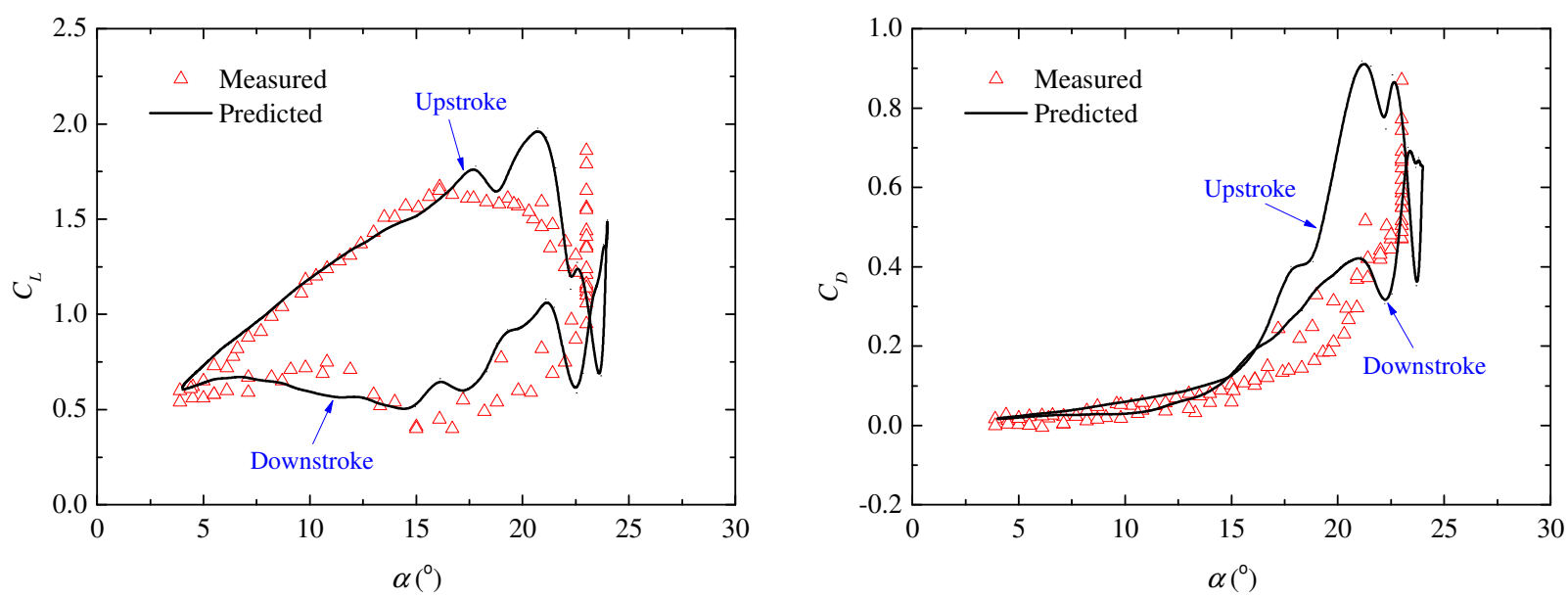

Fig. 5. Lift and drag coefficients for pitch oscillation with $\alpha_{0}=14^{\circ}, \alpha_{\mathrm{m}}=10^{\circ}$ and $k=0.08$

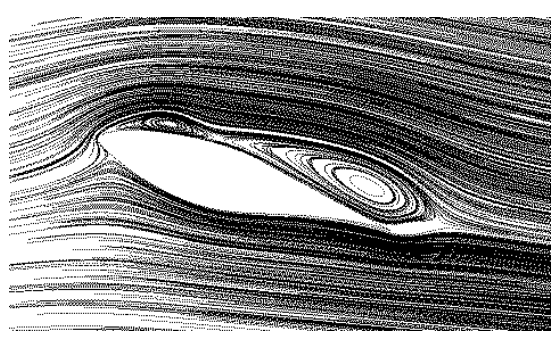

a. $\alpha=17.6^{\circ}$ upstroke

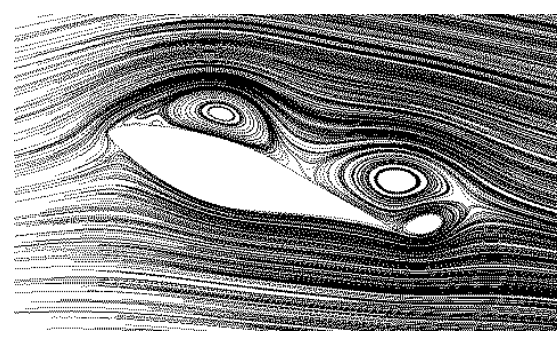

b. $\alpha=18.8^{\circ}$ upstroke

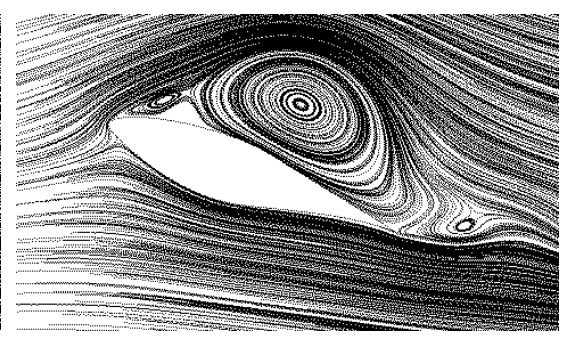

c. $\alpha=20.7^{\circ}$ upstroke

Fig. 6. Streamlines over the airfoil for pitch oscillation with $\alpha_{0}=14^{\circ}, \alpha_{\mathrm{m}}=10^{\circ}$ and $k=0.08$ 

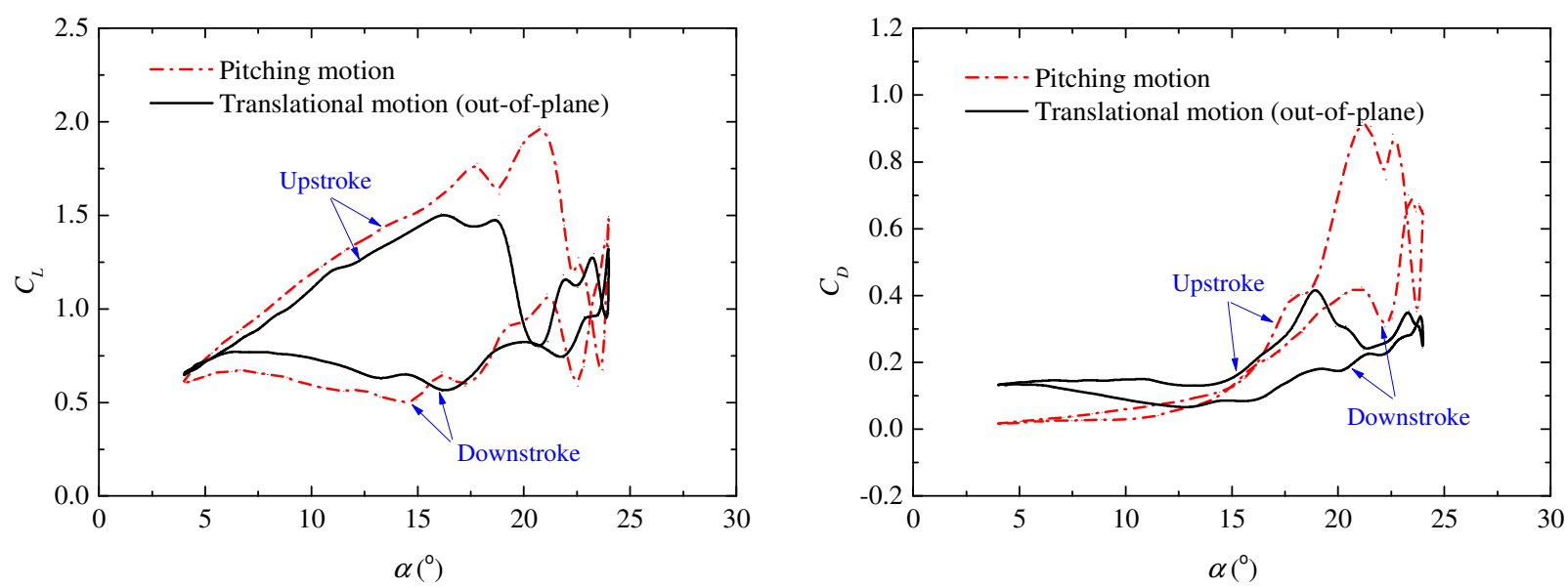

Fig. 7. Lift and drag coefficients for out-of-plane motion as $x=-0.5 \sin (2 \pi f t+\pi / 2)$, compared with those under pitching motion

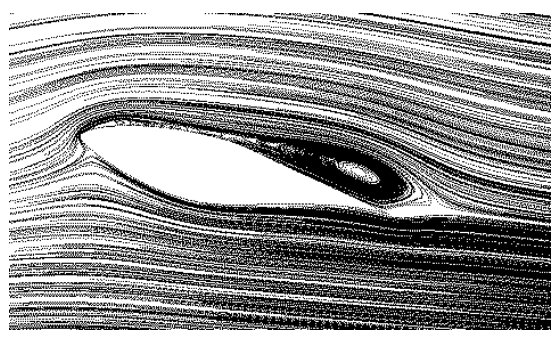

a. $\alpha=16.2^{\circ}$ upstroke

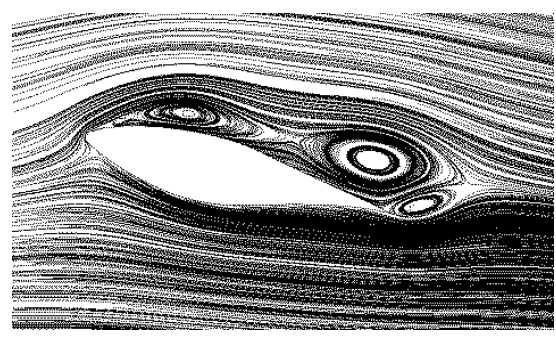

b. $\alpha=17.8^{\circ}$ upstroke

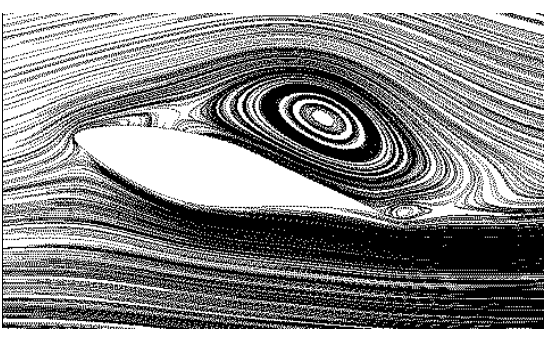

c. $\alpha=19.0^{\circ}$ upstroke

Fig. 8. Streamlines over the airfoil for out-of-plane motion as $x=-0.5 \sin (2 \pi f t+\pi / 2), \alpha$ is the effective AOA
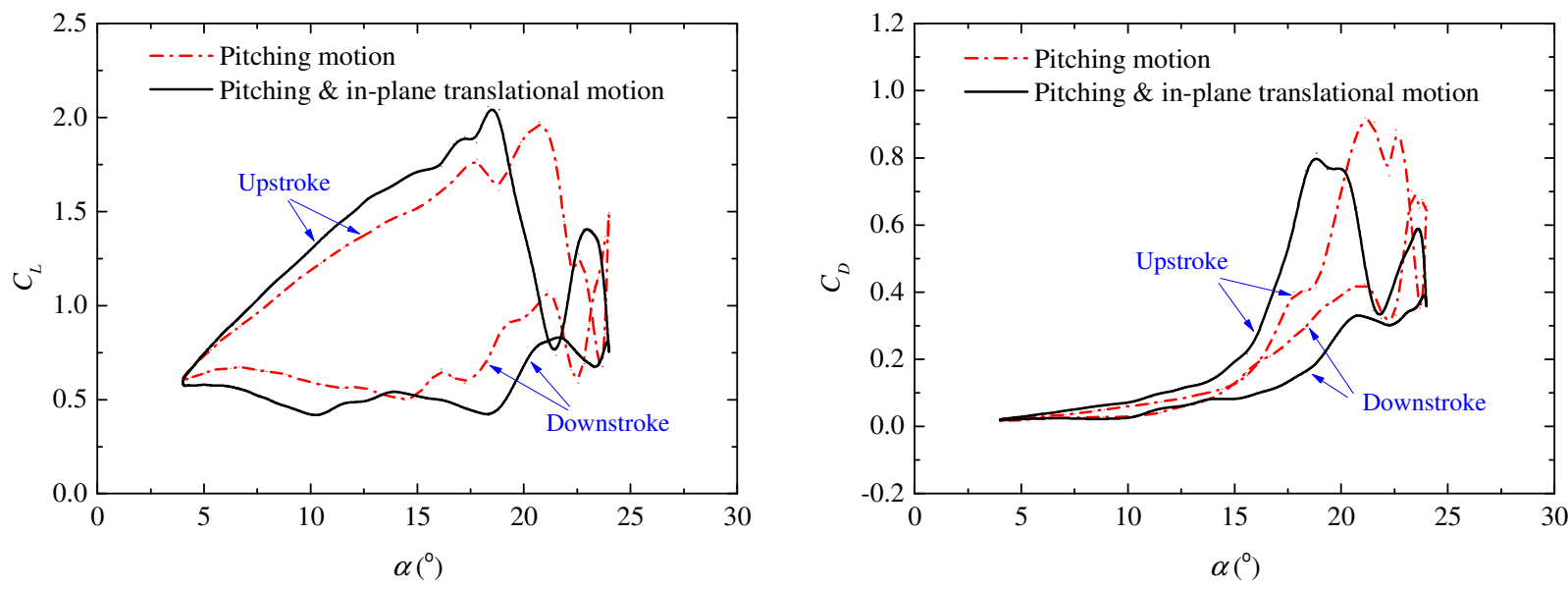

Fig. 9. Lift and drag coefficients for combined pitching and in-plane motion, compared with those under pitching

motion 


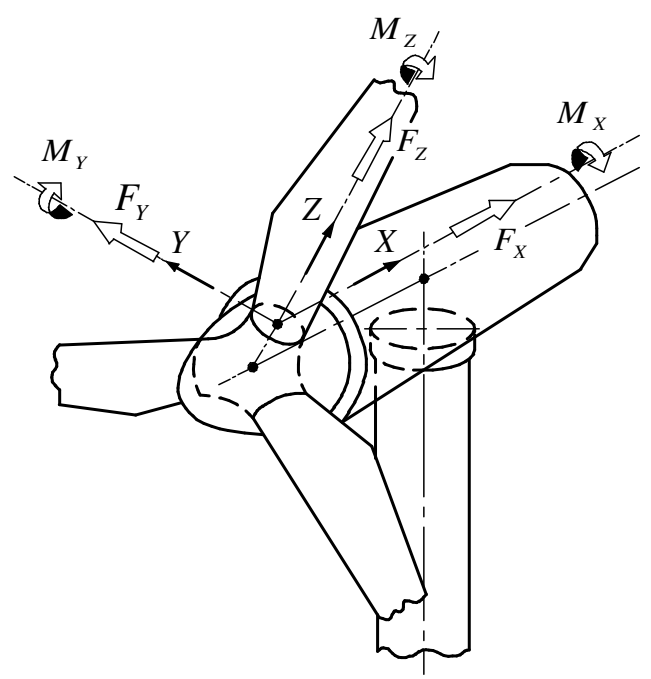

Fig. 10. Blade coordinate system for loads and deflection [40]

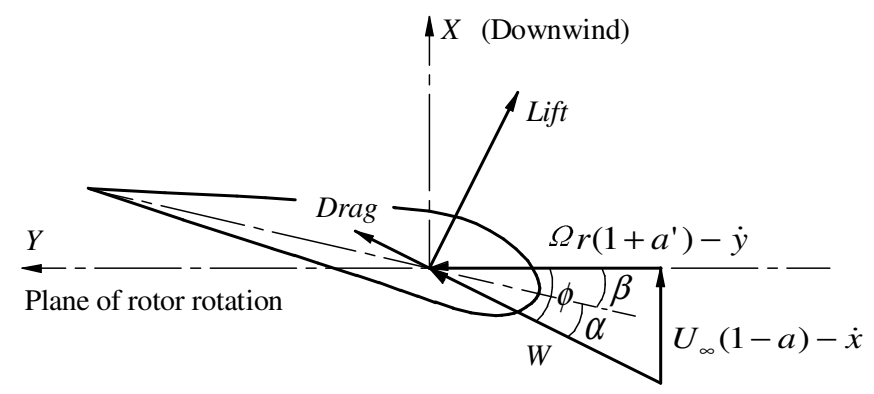

Fig. 11. Velocity diagram for a vibrating blade section 

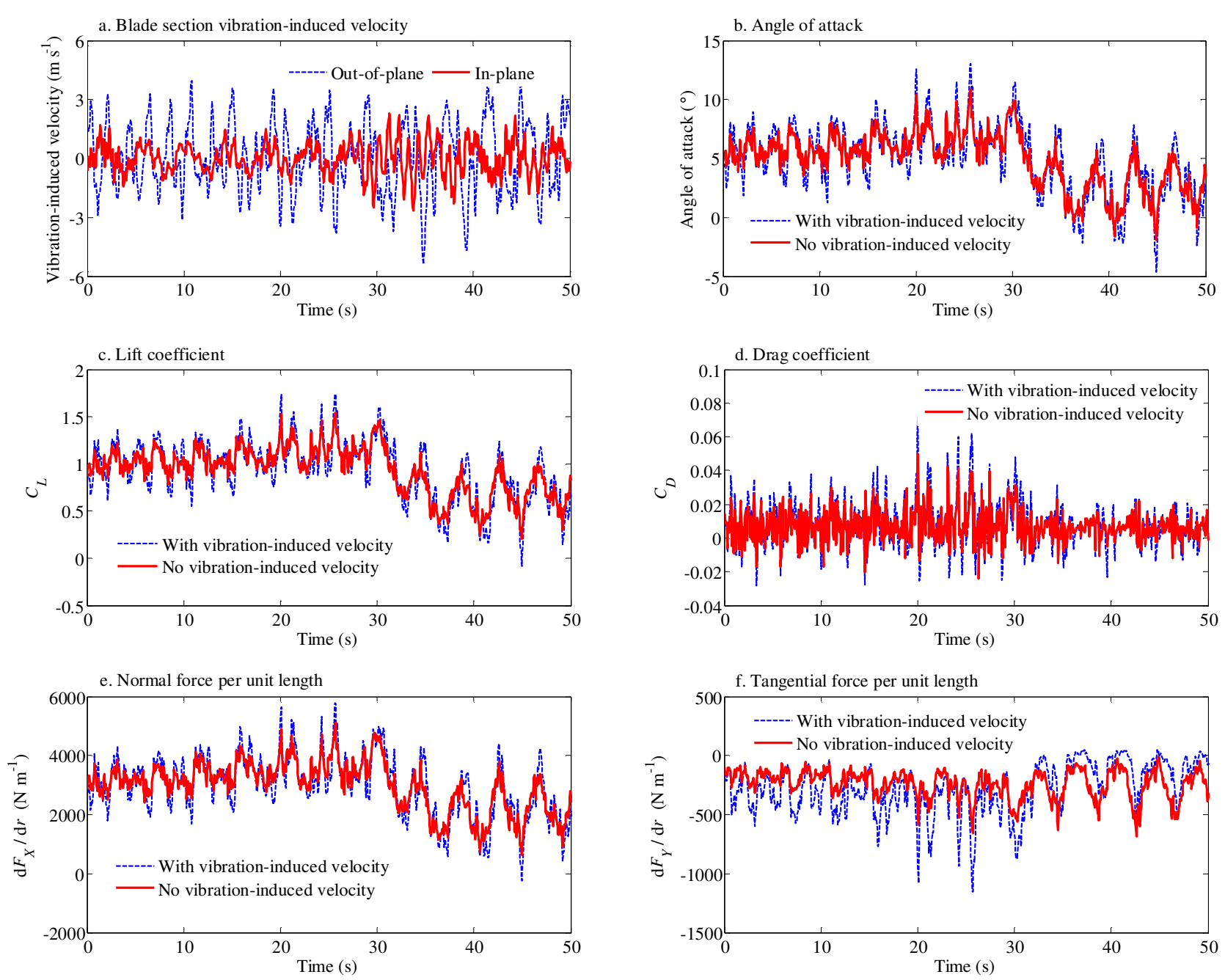

Fig. 12. Time series of vibration-induced velocity, AOA, force coefficient, and aerodynamic force per unit length at $99 \%$ rotor radius of the blade in $12 \mathrm{~m} \mathrm{~s}^{-1}$ turbulent wind
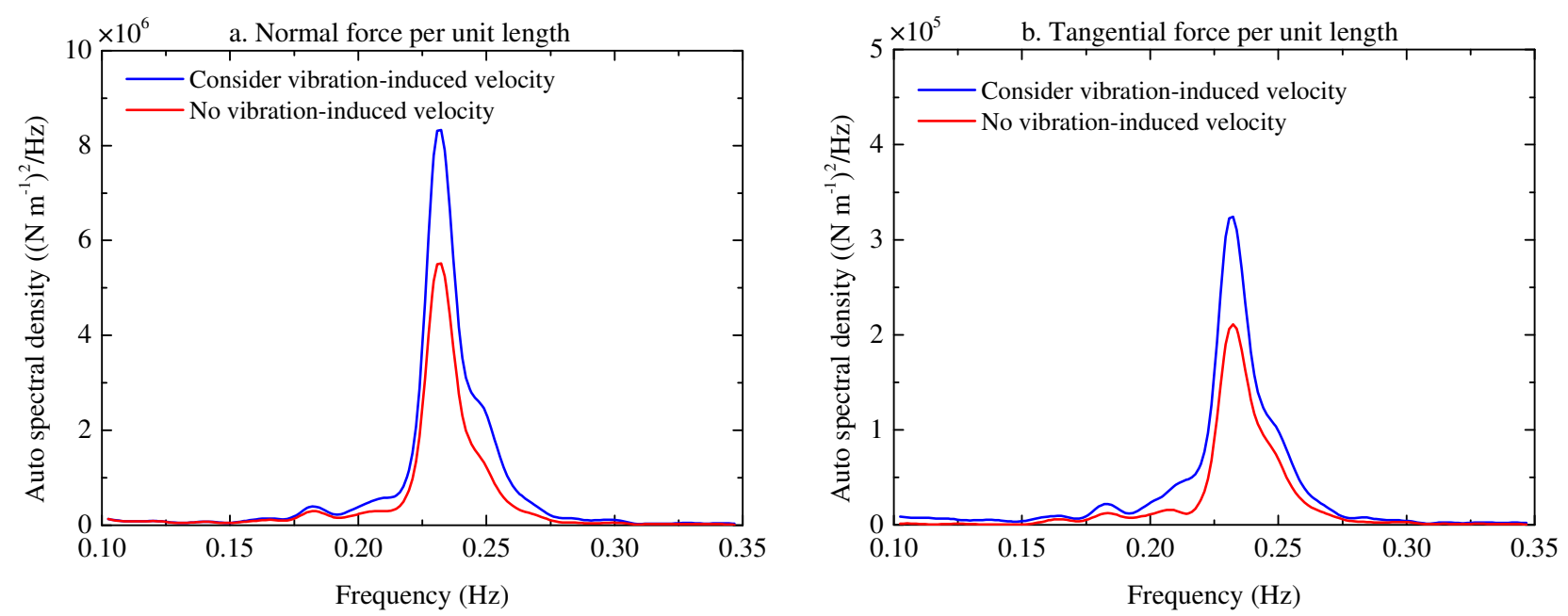

Fig. 13. Spectra of aerodynamic force per unit length at $99 \%$ rotor radius of the blade in $12 \mathrm{~m} \mathrm{~s}^{-1}$ turbulent wind 
Table 1 Parameters of the studied wind turbine

\begin{tabular}{ll}
\hline Wind turbine class & IEC IA \\
Rotor diameter $(\mathrm{m})$ & 118 \\
Blade length $(\mathrm{m})$ & 57 \\
Number of blades & 3 \\
Hub height $(\mathrm{m})$ & 81 \\
Rated wind speed $\left(\mathrm{m} \mathrm{s}^{-1}\right)$ & 12.3 \\
Rotational speed $\left(\mathrm{r} \mathrm{min}^{-1}\right)$ & $7.5-13.9$ \\
Tower height $(\mathrm{m})$ & 79 \\
\hline
\end{tabular}

Table 2 Damage-equivalent load ranges of aerodynamic forces per unit length on two blade sections $\left(S_{X}\right.$ and $S_{Y}$ are the damage equivalent load ranges of $\mathrm{d} F_{X} / \mathrm{d} r$ and $\mathrm{d} F_{Y} / \mathrm{d} r$ respectively without consideration of the blade vibration; $S_{X}{ }^{\prime}$ and $S_{Y}{ }^{\prime}$ are the damage equivalent load ranges of $\mathrm{d} F_{X} / \mathrm{d} r$ and $\mathrm{d} F_{Y} / \mathrm{d} r$ respectively with consideration of the blade vibration. $\delta$ represents relative \% deviation, $\left.\delta=\left(S^{\prime}-S\right) / S\right)$

\begin{tabular}{ccccccccccccc}
\hline $\bar{U}$ & \multicolumn{4}{c}{ Section A at 99\% rotor radius } & \multicolumn{5}{c}{ Section B at 75\% rotor radius } \\
\cline { 2 - 11 }$\left(\mathrm{m} \mathrm{s}^{-1}\right)$ & $\begin{array}{c}S_{X} \\
\left(\mathrm{~N} \mathrm{~m}^{-1}\right)\end{array}$ & $\begin{array}{c}S_{X}{ }^{\prime} \\
\left(\mathrm{N} \mathrm{m}^{-1}\right)\end{array}$ & $\delta_{S X}$ & $\begin{array}{c}S_{Y} \\
\left(\mathrm{~N} \mathrm{~m}^{-1}\right)\end{array}$ & $\begin{array}{c}S_{Y^{\prime}} \\
\left(\mathrm{N} \mathrm{m}^{-1}\right)\end{array}$ & $\delta_{S Y}$ & $\begin{array}{c}S_{X} \\
\left(\mathrm{~N} \mathrm{~m}^{-1}\right)\end{array}$ & $\begin{array}{c}S_{X}{ }^{\prime} \\
\left(\mathrm{N} \mathrm{m}^{-1}\right)\end{array}$ & $\delta_{S X}$ & $\begin{array}{c}S_{Y} \\
\left(\mathrm{~N} \mathrm{~m}^{-1}\right)\end{array}$ & $\begin{array}{c}S_{Y}{ }^{\prime} \\
\left(\mathrm{N} \mathrm{m}^{-1}\right)\end{array}$ & $\delta_{S Y}$ \\
\hline 4 & 475 & 590 & $24 \%$ & 71 & 110 & $55 \%$ & 911 & 948 & $4 \%$ & 138 & 141 & $2 \%$ \\
6 & 1301 & 1534 & $18 \%$ & 164 & 266 & $62 \%$ & 2274 & 2346 & $3 \%$ & 338 & 351 & $4 \%$ \\
8 & 2044 & 2521 & $23 \%$ & 255 & 457 & $79 \%$ & 3881 & 3813 & $-2 \%$ & 594 & 568 & $-4 \%$ \\
10 & 2506 & 3230 & $29 \%$ & 425 & 700 & $65 \%$ & 4590 & 4789 & $4 \%$ & 972 & 1024 & $5 \%$ \\
12 & 3479 & 4474 & $29 \%$ & 562 & 924 & $64 \%$ & 5769 & 6120 & $6 \%$ & 1206 & 1234 & $2 \%$ \\
14 & 4097 & 5171 & $26 \%$ & 653 & 1004 & $54 \%$ & 6879 & 7107 & $3 \%$ & 1461 & 1396 & $-4 \%$ \\
16 & 4263 & 5356 & $26 \%$ & 721 & 879 & $22 \%$ & 7120 & 7410 & $4 \%$ & 1568 & 1171 & $-25 \%$ \\
18 & 4770 & 5840 & $22 \%$ & 895 & 906 & $1 \%$ & 7699 & 7981 & $4 \%$ & 2024 & 1235 & $-39 \%$ \\
20 & 4870 & 6221 & $28 \%$ & 1038 & 906 & $-13 \%$ & 8306 & 8998 & $8 \%$ & 2343 & 1232 & $-47 \%$ \\
22 & 4418 & 5942 & $35 \%$ & 1139 & 925 & $-19 \%$ & 7709 & 8647 & $12 \%$ & 2900 & 876 & $-70 \%$ \\
24 & 5099 & 6453 & $27 \%$ & 1303 & 2033 & $56 \%$ & 8873 & 9099 & $26 \%$ & 3277 & 1255 & $-62 \%$ \\
Overall & 3976 & 5017 & $26 \%$ & 871 & 1271 & $46 \%$ & 6677 & 7063 & $6 \%$ & 2160 & 1179 & $-45 \%$ \\
\hline
\end{tabular}

Table 3 Damage-equivalent aerodynamic bending moments and aerodynamic forces on the blade $(M$ and $F$ are the damage equivalent bending moment and force respectively without consideration of the blade vibration; $M^{\prime}$ and $F^{\prime}$ are the damage equivalent bend moment and force respectively with consideration of the blade vibration. $\delta$ represents relative $\%$ deviation, $\delta=\left(X^{\prime}-X\right) / X$. $)$

\begin{tabular}{rrrrrrrrrrrrr}
\hline$r / R$ & $\begin{array}{c}M_{X} \\
(\mathrm{kN} \mathrm{m})\end{array}$ & $\begin{array}{c}M_{X}{ }^{\prime} \\
(\mathrm{kN} \mathrm{m})\end{array}$ & \multicolumn{1}{c}{$\delta_{M X}$} & $\begin{array}{c}M_{Y} \\
(\mathrm{kN} \mathrm{m})\end{array}$ & $\begin{array}{c}M_{Y}{ }^{\prime} \\
(\mathrm{kN} \mathrm{m})\end{array}$ & \multicolumn{1}{c}{$\delta_{M Y}$} & $\begin{array}{c}F_{X} \\
(\mathrm{kN})\end{array}$ & $\begin{array}{c}F_{X}{ }^{\prime} \\
(\mathrm{kN})\end{array}$ & $\delta_{F X}$ & $\begin{array}{c}F_{Y} \\
(\mathrm{kN})\end{array}$ & $\begin{array}{c}F_{Y}{ }^{\prime} \\
(\mathrm{kN})\end{array}$ & \multicolumn{1}{c}{$\delta_{F Y}$} \\
\hline $5 \%$ & 1157.3 & 904.1 & $-21.9 \%$ & 4248.4 & 4441.7 & $4.5 \%$ & 111.3 & 111.5 & $0.1 \%$ & 35.7 & 26.0 & $-27.1 \%$ \\
$25 \%$ & 707.6 & 585.8 & $-17.2 \%$ & 2791.3 & 2993.1 & $7.2 \%$ & 111.1 & 111.4 & $0.3 \%$ & 34.8 & 24.9 & $-28.6 \%$ \\
$50 \%$ & 288.5 & 268.6 & $-6.9 \%$ & 1262.8 & 1462.1 & $15.8 \%$ & 96.5 & 100.9 & $4.5 \%$ & 24.1 & 20.1 & $-16.5 \%$ \\
$75 \%$ & 66.3 & 66.1 & $-0.3 \%$ & 302.7 & 382.3 & $26.3 \%$ & 43.6 & 53.0 & $21.5 \%$ & 9.8 & 9.1 & $-7.5 \%$ \\
$95 \%$ & 1.2 & 1.8 & $49.8 \%$ & 5.3 & 6.7 & $28.3 \%$ & 6.0 & 7.6 & $26.4 \%$ & 1.3 & 1.7 & $30.7 \%$ \\
\hline
\end{tabular}

